\title{
Geochemical characteristics of sediments and massive sulfides from sediment-hosted hydrothermal systems at South Okinawa Trough
}

FENG-HSIN HSU $^{1}$, CHIH-CHIEH SU ${ }^{1}$, SHEIN-Fu WU ${ }^{1}$, HSIAO-FEN LEE ${ }^{2}$, WeI-TEH JIANG ${ }^{3}$, SONG-CHUEN CHEN ${ }^{4}$, JUI-ER CHEN ${ }^{4}$, AND YUN-SHUEN WANG ${ }^{4}$

${ }^{1}$ Institute of Oceanography, National Taiwan University, Taipei 10617 Taiwan (fenghsinhsu@gmail.com; donccsu@ntu.edu.tw)

${ }^{2}$ National Center for Research on Earthquake Engineering, National Applied Research Laboratories, Taipei 10668 Taiwan

${ }^{3}$ Department of Earth Sciences, National Cheng Kung University, Tainan, 70101, Taiwan

${ }^{4}$ Central Geological Survey, Ministry of Economic Affairs, New Taipei City, 23568 Taiwan

The hydrothermal systems of South Okinawa Trough develop at the sediment-rich continental margin with their fluid affected by fluid-sediment interaction, such as containing high $\mathrm{CO}_{2}$ due to the thermal decomposition of organic matter in sediments; and the chemical compositions of hydrothermal deposits/precipitations may subsequently be modified. Here, we reported the geochemical characteristics of sediments and massive sulfide ores collected from the Geolin Mounds (GLM), Penglai Fault Zone (PFZ), and Mienhua Volcano (MHV) hydrothermal field at South Okinawa Trough. In addition to gas flames captured by EK60, unique geochemical features in pore water (high ${ }^{3} \mathrm{He} /{ }^{4} \mathrm{He}$ values and strongly $\mathrm{Mg}^{2+}$ consumption with depth) and hydrothermal massive sulfides on the seafloor have confirmed their vigorous hydrothermal activities. At GLM anf PFZ sites, sediments related to hydrothermal alteration were found at few specific layers with significant enrichments of $\mathrm{Au}, \mathrm{Ag}, \mathrm{As}$, $\mathrm{Bi}, \mathrm{Cu}, \mathrm{Cd}, \mathrm{Pb}, \mathrm{Sb}, \mathrm{Sn}$ and $\mathrm{Zn}$ as well as low-/very lowsulfidation minerals, such as pyrrhotite, sphalerite, and galena etc. The positive relationships of $\mathrm{Au}, \mathrm{Ag}, \mathrm{As}, \mathrm{Bi}, \mathrm{Cu}, \mathrm{Cd}, \mathrm{Pb}$, $\mathrm{Sb}, \mathrm{Sn}$ and $\mathrm{Zn}$ with $\mathrm{Ag}$ preliminarily indicated hydrothermally enriched metal elements. Massive sulfides collected from GLM, MHV and PFZ sites are characterized by extreme enrichments of $\mathrm{Ag}, \mathrm{As}, \mathrm{Bi}, \mathrm{Cu}, \mathrm{Cd}, \mathrm{Pb}, \mathrm{Sb}, \mathrm{Sn}$ and $\mathrm{Zn}$. They showed similar patterns with sulphide-rich and sulphate-rich ore deposits collected from the Mid-Okinawa Trough and East Pacific Rise sulfide deposits except for slightly enriched $\mathrm{Sn}$ and depleted Ni. The geochemical characteristics observed at South Okniawa Trough might reflect the influence of hydrothermal fluid-sediment interaction on hydrothermal mineralization. 